\title{
Mining Machinery Maintenance Key Performance Indicators Improvement at the Nordgold Taparko Mine
}

\author{
Drissa Mohamed Malo ${ }^{1, ~}$, Arsene Kpoda ${ }^{2}$, Hamidou Kabre ${ }^{3}$, Gaetan Ouermi ${ }^{2}$ \\ ${ }^{1}$ Mechanical Engineering Department, Faculty of Engineering, Istanbul University, Istanbul, Turkey \\ ${ }^{2}$ Gold Mine Plant, Nordgold Somita, Taparko, Burkina Faso \\ ${ }^{3}$ Mechanical Engineering Department, Institute of Technology, Nazi Boni University, Bobo-Dioulasso, Burkina Faso
}

Email address:

madrmo1993@gmail.com (D. M. Malo)

${ }^{*}$ Corresponding author

\section{To cite this article:}

Drissa Mohamed Malo, Arsene Kpoda, Hamidou Kabre, Gaetan Ouermi. Mining Machinery Maintenance Key Performance Indicators Improvement at the Nordgold Taparko Mine. European Business \& Management. Vol. 5, No. 6, 2019, pp. 84-92.

doi: $10.11648 /$ j.ebm.20190506.13

Received: October 12, 2019; Accepted: November 8, 2019; Published: December 4, 2019

\begin{abstract}
This research work is about the maintenance performances analysis and improvement of miscellaneous mining machinery and equipment used at the NORDGOLD SOMITA mining plant. The study started with a brief introduction to the mining activity. Then a general presentation of the TAPARKO mining site and its history was performed. Moreover, an overview of the equipment which is used on the mining site and its mechanical applications and utility was carried out. The maintenance plays a vital and essential role in the mining sector. A good maintenance management provides the plant with safe and effective equipment. One of the main issues in maintenance planning is to make sure that the planned maintenance tasks have positively influenced the productivity of the plant as expected. In order to achieve the desired performance at an optimal cost, the maintenance department has to keep monitoring the maintenance performances. This will help the company to reach the maximum profitability. Some maintenance key performance indicators exist and they allow the maintenance planners to monitor the maintenance effectiveness in a defined interval of time. Thus, a decrease of maintenance performances can be quickly detected and prompt corrective measures can be taken. Therefore, the necessary data was collected and an analysis of those indicators was accomplished. The obtained results revealed that. Last but not least, through a thorough examination of these results, some suggestions have been made in order to improve the mechanical maintenance practices in the mining sector.
\end{abstract}

Keywords: Mining, Machinery, Maintenance, Key Performance Indicators, Performance Measurement

\section{Introduction}

Mining is the extraction of valuable minerals such as gold and silver from the earth usually from an orebody or lode. From ancient times to the present, mining activities have played an important role in the world [1]. The valuable minerals extraction has been providing mankind with a method of creating wealth since the prehistorical age. The history of mining cannot be separated from that of civilization. Indeed, there were many important cultural areas such as the stone, bronze, steel and iron ages which were associated with various minerals.

There are five main stages in the life of a mine and they are the prospection, the exploration, the development, the exploitation and the reclamation. The prospection which is the first stage is the search for ores and other valuable minerals. The second stage which is the exploration helps determine the size and the value of a mineral deposit through the use of methods such as radiometric evaluation techniques. The third stage is the development and is the action of opening a mineral deposit for exploitation. The exploitation, the fourth stage of mining, is the one where the actual extraction or recovery of minerals from the earth is performed. There are two main exploitation methods which are the surface mining and underground mining. Underground mining methods are methods in which the ore is extracted from deep within the earth [2]. The final stage is the reclamation which is the process of closing a mine, 
revegetating, and restoring the water and land values.

NORDGOLD is a worldwide company specialized in gold production and which was founded in 2007 in Russia. The company is one of the leaders fastest growing mining companies throughout the world. Indeed, its assets span from America to Siberia. NORDGOLD owns 10 mines in four (04) countries which are Russia, Kazakhstan, Guinea and Burkina Faso. The TAPARKO mine is one of them. The TAPARKO ore deposit was discovered in 1980 by the geology department of the Burkinabe Government. Later further explorations were done until 2004 when the mining license was delivered. The TAPARKO MINING COMPANY (SOMITA) has been co-owned by NORGOLD and the government of Burkina Faso since August 2008. The TAPARKO Gold Mine is located in NAMANTENGA province, $200 \mathrm{~km}$ northeast of the capital city of Burkina Faso, Ouagadougou. The site is accessible through a fully asphalted road. The site was acquired by NORGOLD one year after its creation. The TAPARKO mining site holds a historical significance for the country since it was the first private gold mine built in Burkina Faso.

\section{Review of Mining Machinery and Mineral Processing}

\subsection{Related Works}

In an empirical analysis of maintenance performances by Liliane et al. [3], an industrial survey was carried out in order to review the performance measurement practices in maintenance management. On the basis of collected responses of the survey, key performance indicators analyses were performed. One of the main purposes of this work was to determine the effects of manufacturing environment and maintenance objectives on key performance indicators. The study demonstrated that most widespread key performance indicators in the industrial sector are lagging indicators such as equipment, maintenance cost and safety performances.

Another study was done by Oliveira et al. [4] to determine the use of maintenance performance indicators by companies of the Industrial Hub of Manaus. A questionnaire was then sent to industrial companies. The study revealed that the use of performance indicators in maintenance is not sufficient and mainly depends on the number maintenance crew size and the number of equipment.

In this research work, some of the most popular maintenance key performance indicators were identified and used to carry out performance analyses of the TAPARKO mine plant. The particularity of this study is that it is intended for the mining sector which is one of the fastest growing industrial sectors in the world. The study offers a method to monitor and detect performance decreases of key equipment and production facilities at the mine.

\subsection{Stationary Equipment}

a) Jaw crushers: They are one of the most common crushers in the world. They are used to reduce the size of ores. They use the compressive force for breaking the rocks. This pressure is generated by two vertical thick manganese plates called the jaws of the machine. One of the jaws is stationary whilst the other one is mobile. They form a V-shaped cavity where the rock breaking process is performed and which is called the crushing chamber [5]. They are mostly used for primary ore breaking operations.

b) Cone crushers: They are machines that crush the material by squeezing or compressing feed material between a moving circular part and another stationary circular part. They are used in the mining sector for the fragmentation and production of ores and rock materials [6]. The size of the reduction depends on the gap between the two circular crushing parts.

c) Ball mills: They are mostly used in the mining industry to finalize the ore crushing process in presence of water. They are cylindrical machines whose role is to grind rocks and other solid materials into fine powder. The cylinder rotates around a horizontal axis. Through this rotation motion, the material layers close to the cylinder wall will break. The speed of the motion will help generate a sliding stream that consists of several layers of balls separated by layers of the material to be ground [7]. The watery material that exits the mill is called the pulp. There are two ball mills at the TAPARKO plant.

\subsection{Mobile Equipment}

a) The dump truck or dumper: They are used to transport the excavated material to the ore treatment plant. A typical dump truck is equipped with an open-box bed, which is hinged at the rear and equipped with hydraulic rams to lift the front, allowing the material in the bed to be deposited ("dumped") on the ground behind the truck in a feeder or on a delivery site.

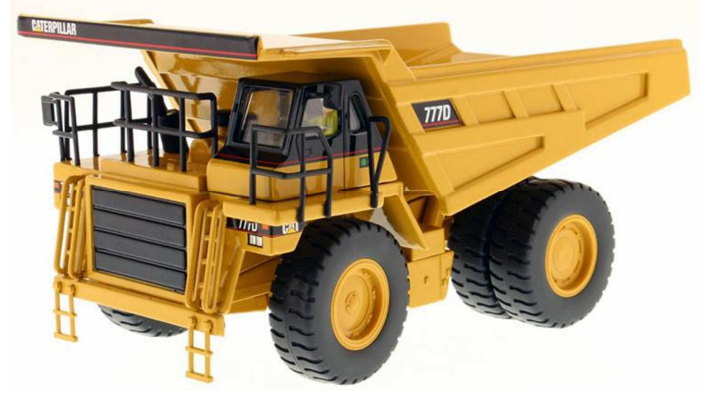

Figure 1. Dump truck.

b) The backhoe loader: The backhoe loader's main function is to load the dump trucks or to move the material from a place to another one. It is a combination of machines also called tractor backhoe. It is one of the most versatile machines. 


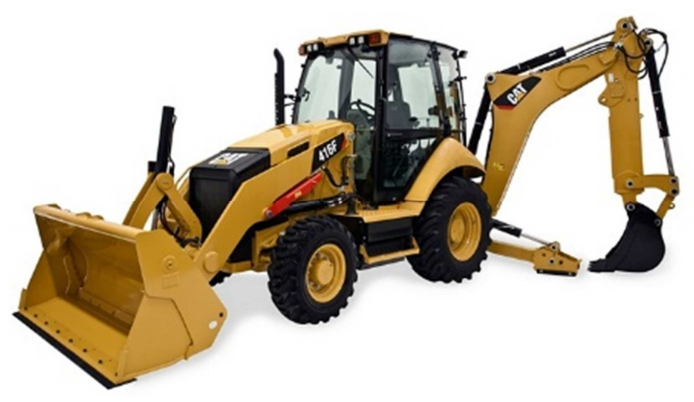

Figure 2. Backhoe loader.

c) The hydraulic excavator: Excavators are heavy machines used on construction, road construction and mining sites for excavating operation including earthwork. They are also called diggers, mechanical shovels or 360 (for 360 degrees excavators).

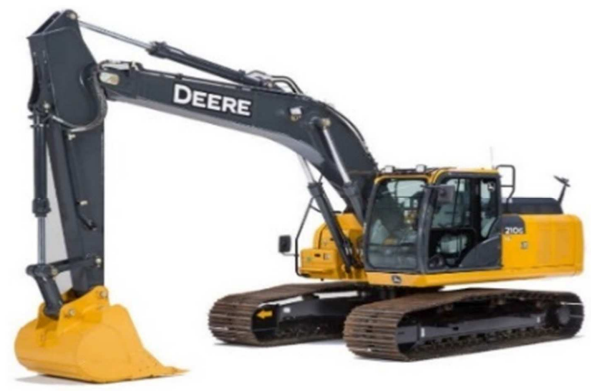

Figure 3. Hydraulic excavator

\subsection{Mineral Processing}

The mining method used at the TAPARKO mine is the open cast mining method. Mineral processing is the process of separating precious and useful minerals from their ores [8]. Gold extraction designates the set of all needed stages to extract the gold from its ore [9]. After the blasting and collection operations, the ore is carried to the plant where it will be processed. This process involves two major steps which are comminution and separation. The process starts with the crushing operation. There are 4 main crushing areas at the TAPARKO mine plant:

a) A single stage crushing area for the smooth ore.

b) Two 3 stages crushing area (the new one and the old one) for raw ore.

c) A crushing area for the rejects of the other crushers and ball mills.

After the crushing operation, the crushed ore is sent to the ball mills to be ground in presence of water. The obtained watery stuff is the pulp which will be sieved in the cyclones and sent to the tanks for the carbon lixiviation process.

The leaching processes used at the TAPARKO mine are mainly the Carbon-In-Leach (CIL) and the Carbon-In-Pulp (CIP) methods. To leach gold, both carbon and oxygen are indispensable [10]. This can be shown in Bödlander's two reactions (1) and (2) that result into Elsner's reaction (3).

$$
2 \mathrm{Au}+4 \mathrm{CN}^{-}+\mathrm{O}_{2}+2 \mathrm{H}_{2} \mathrm{O} \Leftrightarrow 2 \mathrm{Au}(\mathrm{CN})_{2}^{-}+2 \mathrm{OH}^{-}+\mathrm{H}_{2} \mathrm{O}_{2}(1)
$$

$$
\begin{gathered}
2 \mathrm{Au}+4 \mathrm{CN}^{-}+\mathrm{H}_{2} \mathrm{O}_{2} \Leftrightarrow 2 \mathrm{Au}(\mathrm{CN})_{2}^{-}+2 \mathrm{OH}^{-} \\
4 \mathrm{Au}+8 \mathrm{CN}^{-}+\mathrm{O}_{2}+2 \mathrm{H}_{2} \mathrm{O} \Leftrightarrow 4 \mathrm{Au}(\mathrm{CN})_{2}^{-}+4 \mathrm{OH}^{-}
\end{gathered}
$$

The pulp flows through all eight tanks which are one the CIL plant. Then from tank 8 , carbon is added. This carbon will capture the gold which dissolved in the cyanide till tank 1. After that, the elution, which is the set of all needed processes necessary to capture the carbon, is performed. It also includes the extraction process of gold from the carbon and its (carbon's) regeneration to be reused as a capturer for the dissolved gold. After leaving the elution tank, the carbon is immediately sent to the carbon regeneration or recycling area.

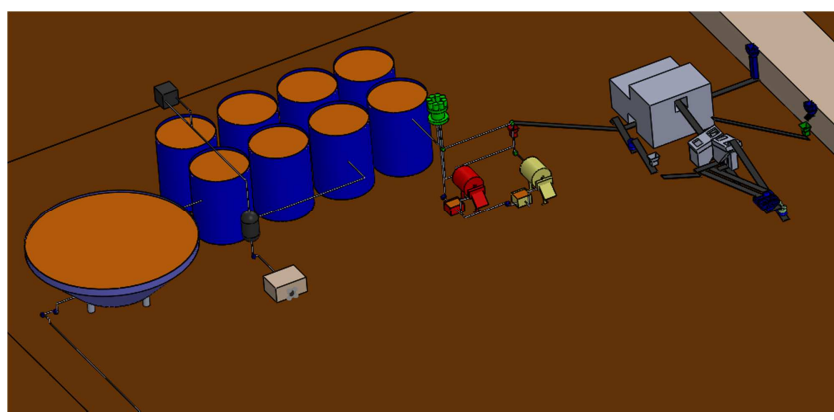

Figure 4. Plant plan

\section{Methodology}

The data was collected for approximately two weeks, between the 03/09/2019 and the 20/09/2019. The maintenance is the work needed to keep a machine or any other item in good operating conditions. The main objectives of the maintenance are ensuring the plant functions until its planned lifetime end, ensuring the plant's cost effectiveness and ensuring the plant's safety [11]. Mechanical breakdowns problems have the highest impact on the plant's operations. The maintenance crew at the TAPARKO mine consists of 2 main departments. There is a mechanical and an electrical crew. Each one of these teams is split into two (02) shifts that replaces each other on a weekly basis. So, except the department managers and superintendents, most of the maintenance crew employees work on a 7-7 shift system basis which means that they work for seven (07) days and can have some rest for seven (07) days. The daily workload is approximately. The mechanical maintenance crew is in charge of all mechanical maintenance or repair works at the plant. They perform both preventive and corrective maintenance tasks. Each shift team consists of ten (10) mechanics, six (06) welders, two (02) supervisors, a store keeper and one (1) planner. The electrical maintenance crew consists of five (05) electricians, one (01) instrument technician. They are in charge of the electrical maintenance and repair tasks. Both shift teams have a common technical drawer, mechanical project manager, superintendent and manager.

Nowadays in the industrial sector, maintenance departments play one of the most vital roles because of their 
ability to have an economic balancing effect for their companies [12]. The maintenance department is one of the key departments for the good working order of a company [3]. Indeed, serious breakdowns, interruptions, slower production rate, and even safety hazards may be the consequences of the absence of a maintenance department in a company [13]. The cost of maintenance and its influence on the productivity of the plant is too important for plant managers to not take it into accounts. Thus, performance measurement is very important for maintenance management. The mining industry faces unique challenges in term of preventive and corrective maintenance because of the isolation of most mining sites from the agglomerations, making spare parts supply sometimes challenging and troublesome. Apart from the transport problem, work conditions are also sometimes hard because of the natural conditions of the areas where the mines are located. Downtimes are very critical in mining, so, it is sometimes necessary for the employees to work under rainy or dusty, extremely hot or cold conditions. Thus, maintenance is a crucial factor in a mining plant's performance.

A maintenance key performance indicator is a measurable value that shows how effectively a company is reaching its key maintenance objectives. Well defined key performance indicators could help identify and fill the gap between the actual performances and the expected ones. The most commonly used ones can be mainly classified into three (3) categories which are the equipment performance, the cost performance and the process performance [14]. So, there are numerous maintenance key performance indicators but only few of them are really used by the industries [4]. Some categories and indicators have popularly been recognized by the industrial sector and are widely used all over the world to evaluate and monitor the maintenance performances and will be used to analyze the maintenance performances of the TAPARKO plant.

Maintenance effectiveness: It is a measure of the amount of maintenance downtime that is necessary to keep the equipment in acceptable operating conditions. The effectiveness of the maintenance is significantly dependent on the maintenance strategies and planning adopted by the company [15]. One of the main goals on a mining plant is to constantly maximize the equipment's operational availability at minimum cost. The maintenance effectiveness is expressed in percentage and it is equal to the ratio of the operating time to the operating time plus the downtimes. Its standard minimum value is $95 \%$.

$$
\text { Maintenance Effectiveness }=\left(\frac{\text { operating Time }}{\text { operating Time }+ \text { Down Time }}\right) \times 100 \%
$$

Preventive inspection effectiveness: It represents the effectiveness of preventive inspections that are regularly carried out on the plant. Setting up an efficient system of preventive inspection helps the maintenance manager run smoothly the plant's maintenance work. Preventive inspections prevent many unexpected malfunctions. The preventive effectiveness is the ratio of the preventive repair man hours to the preventive inspection man hours and is

expressed in percentage. The higher the preventive inspection effectiveness value is, the more effective the preventive inspections are. A high preventive inspection effectiveness could also indicate that the inspection frequency is too low and has be increased in order to reach the balance between preventive repair man hours and preventive inspection man hours.

$$
\text { Preventive Inspection Effeciveness }=\left(\frac{\text { Preventive Repair Man Hours }}{\text { Preventive Inspection Man Hours }}\right) \times 100 \%
$$

Ratio of preventive to breakdown maintenance: This key performance indicator shows the effectiveness and the impact of the planning practices on breakdown maintenance. Data such as the preventive repair man hours, the preventive
Maintenance backlog: It is a very important key performance indicator that allows the planners and plant managers to have an idea about the amount of work that needs to be completed for outstanding reasons such as safety preservation and further plant breakdown avoidance. For instance, in case it is required to change the balls of a ball mill every 3000 hours, when the time limit is reached, the ball change task will remain in the maintenance backlog until inspection man hours and the breakdown man hours must be collected in other to calculate the ratio of preventive to breakdown maintenance.

$$
\text { Backlog = Total Maintenance Man Hours on Outstanding Work Orders }
$$

Percentage of scheduled man hours planned: It is a measure of planning practices effectiveness. It represents the it is completed. The longer it remains there, the more critical it becomes. Up to a certain value or level, maintenance backlog is acceptable and almost unavoidable. This maximum value is predefined according to the type of the plant and to the needs and objectives of the company. This indicator helps the plant managers and the planners to keep the balance between the allocated resources and the costs associated with maintenance [16].

ratio of planned scheduled man hours to the total weekly scheduled man hours. This key performance indicator (KPI) 
shows how well the planning mechanism perform on the

overall working order of the equipment or the plant.

$$
\% \text { Scheduled Man Hours Planned: }\left(\frac{\text { Planned man hours on weekly schedule }}{\text { Total weekly scheduled man hours }}\right) \times 100 \%
$$

Percentage of scheduled compliance: This key performance indicator helps plant managers and maintenance planners to measure the compliance of the scheduling process. Data such as the scheduled man hours completed and total weekly scheduled man hours must be collected in order to be able to determine the scheduled compliance. The

$$
\% \text { Scheduled Compliance }=\left(\frac{\text { Scheduled Man Hours Completed }}{\text { Total Weekly Scheduled Man Hours }}\right) \times 100 \%
$$

Percentage of planning effectiveness: It represents a measure of the planning process compliance. This key performance indicator (KPI) indicates how many planned jobs are completed with comments from the technicians. When the planners are establishing a schedule, they have to make sure that all the conditions are met so that the scheduled man hours completed represents the actual amount of time spent executing scheduled maintenance. The percentage of scheduled compliance represents the ratio of scheduled man hours completed to the total weekly scheduled man hours.

$$
\text { Percentage of planning effectiveness }=\left(\frac{\text { Number of Scheduled Jobs completed with comments }}{\text { Total Number of Scheduled Jobs completed }}\right) \times 100 \%
$$

$\%$ Rework: It is the percentage of correction of defective or failed during or after maintenance work. It is a maintenance action performed on inefficiently or improperly pre-maintained equipment [17]. The reason of the maintenance inefficiency could be the poor workmanship, the poor design or the lack of proper utility equipment. Rework tasks consist of disassembly, reassembly, repair and replacement actions. The purpose of the rework is to repair or improve the part in order meet specifications. Data such as the rework man hours and maintenance work hours. The rework man hours represent the total amount of time required for rework times the number of crew members used to perform these tasks. The maintenance work hours represent the total and actual amount of man hours spent performing corrective and preventive maintenance tasks on the plant or on some specific equipment.

$$
\% \text { Rework }=\left(\frac{\text { Rework Man Hours }}{\text { Maintenance Man Hours }}\right) \times 100 \%
$$

$\%$ Failures Investigated: It represents the percentage of equipment or plant breakdowns and failures that were thoroughly investigated. It is a measure of the maintenance department's effort to continuously improve. The purpose of the investigation for the maintenance department is to reveal the failure causes and mechanisms in order to prevent future occurrences. Data such as the number of corrective job tickets investigated and the total number of corrective jobs have to be collected. The number of investigated corrective job tickets represents the number of failures' root causes found and solutions investigated. The total number of corrective jobs represents the total number of maintenance tasks executed on defects which led to equipment breakdown.

$$
\% \text { Failure Investigated }=\left(\frac{\text { Number of Corrective Job Tickets }}{\text { Total Number of Corrective Job Tickets }}\right) \times 100 \%
$$

Mean time between failure (MTBF): It is a key performance indicator that has been commonly used for over 70 years [18]. It represents the average time between the failures or breakdowns of some equipment or a plant. It can also be considered as a prediction of the reliability of the equipment [19]. The mean time between failure can be measured for a specific component of equipment, for some specific equipment or for the whole plant [20]. The mean time between failure has an influence on both the reliability and the availability of the equipment. Most of the time, the difference between the reliability and the availability is misunderstood or unknown. On one hand, the reliability is the ability of a mechanical or electrical system to perform the tasks it was assigned to and under certain work conditions for a predefined interval of time. On the other hand, the availability is the ability of a system to be in acceptable operating conditions in order to be accessible for use.

$$
M T B F=\frac{\text { operating Time }}{\text { Number of failures or breakdown events }}
$$

Mean time to repair (MTTR): This key performance indicator (KPI) is a maintenance metric which indicates a measure of the maintainability of repairable equipment. In other words, it represents the average amount of time required to repair some failed equipment or one of its components. The mean time to repair measure the interval of time between the start of the failure and the time the equipment becomes operational again. While calculating this key performance indicators, planners or planning managers have to take into account the time needed to notify the crew members, to allow the equipment to cool down, to 
disassemble the equipment when deemed necessary, to diagnose and fix the defect which led to the breakdown or failure, to reassemble the equipment and finally to start back the production process. Data such as the number of failure or breakdown events and downtimes are needed to calculate the mean time to repair (MTTR). The down time represents the average maintenance time needed to keep the machinery functional and operational. The mean time to repair is mathematically the ratio of the downtime to the number of failures or breakdown events.

$$
M T T R=\frac{\text { Down Time }}{\text { Number of failures or breakdown events }}
$$

\section{Results and Discussion}

\subsection{The “Old 3 Stages" Crushing Area Key Performance Indicators Results}

This crushing area is the oldest, busiest and more productive one at the TAPARKO mine. It is named "old" because of the fact that it was the TAPARKO mine's first implanted crushing area. It consists of very robust and powerful machinery and conveyor belts which carry and transport ore through the whole circuit. It is the main crushing area of the mine. The maintenance effectiveness of the old 3 stages is $91.48 \%$. From the results of previous works, the minimum recommended value for this indicator is $95 \%$. The maintenance effectiveness at the TAPARKO mine was slightly below the recommended value during this period of time. Several factors such as a planned overall shut down, the rainy season and the age of the equipment could be the causes of this situation. This equipment has been working for almost one decade and a half. This could explain the growth of down time and the increase of the maintenance effort required during this interval of time.

The mean time between failure of the "old 3 stages" crushing area was 43.38 hours per breakdown or failure events during this period of time. It means that there was a breakdown or failure events almost every two days. For an equipment of this age, a mean time between failures of two (02) days is quite good.

The mean time to repair of the "old 3 stages" crushing area is 3.25. This relatively big amount of time is justified by the fact that most of the failures and break down of the "old 3 stages" area require some extra utility equipment such as crane trucks. In case of breakdown, it is also sometimes necessary to drain all the ore from the broken-down part to allow the technician to identify and fix the issue. So, during this period of time the required maintenance effort increased.

The preventive inspection effectiveness of the "old 3 stages" crushing area is 3.83 . It is medium value which means that the preventive inspections on the "old 3 stages" crushing area were not optimal during the defined period of time. This could be explained by the lack of man power or sometimes the lack of time. Breakdown happened a lot at the same period on the plant interrupting the daily inspections.

The value of the ratio of preventive to breakdown maintenance of the "old 3 stages" crushing area is 19.55. The minimum recommended value is 16 . It means that the actual value was slightly higher than the recommended one during the given interval of time. Therefore, maintenance practices are very good and effective. However, it is necessary not to exceed the current maintenance man hours to avoid over maintaining the equipment.

\subsection{The "New 3 Stages" Crushing Area Key Performance Indicators Results}

The maintenance effectiveness of the "new 3 stages" crushing area is $78.13 \%$. From the results of previous works, the minimum recommended value for this indicator is $95 \%$. Thus, the required maintenance effort increased and the maintenance practices were not effective during this period of time. The operating conditions also got worse.

The mean time between failures of the "new 3 stages" crushing area is 42.19 hours. This value is acceptable and it means that the maintenance mechanisms during this interval of time were good and effective enough. The required maintenance effort also decreased.

The mean time to repair of the "new 3 stages" crushing area was 11 hours in the given time. This relatively high mean time to repair resulted from the fact that a breakdown occurred on $7^{\text {th }}$ of October and took more than two three days to be repair. It means that the maintenance practices and mechanisms during the given interval of time were not effective and the required maintenance effort increased.

The preventive inspections effectiveness of the "new 3 stages" crushing area is 15.89 . This high value indicates that the preventive inspections were effectively conducted and that they allowed maintenance crew to avoid further breakdowns and failures events.

The ratio of preventive to breakdown maintenance of the "new 3 stages" crushing area is 2.12. The minimum recommended value is 16 . This low actual value could be explained by the fact that some defects were probably not reported by crew members to the planners and maintenance managers. The preventive maintenance mechanisms were also not optimal during this interval of time.

\subsection{The Pebble Crushing Area Key Performance Indicators Results}

The maintenance effectiveness of the pebble crushing area is $79.1 \%$. The minimum recommended value is $95 \%$. This relatively low value indicates that the operating conditions deteriorated. Indeed, the pebble crusher used at the TAPARKO mine plant is not meant to crush wet ore. However, in this rainy season it is almost impossible to keep the ore dry. The required maintenance effort decreased as well.

The mean time between failures of the pebble crushing area is 342 hours. This relatively high value could be explained by the fact that only a breakdown occurred in the given interval of time although it lasted for days. The failure and breakdown frequencies decreased. 
The mean time to repair of the pebble crushing area is 90 hours. This relatively high value indicates that corrective maintenance practices were not effective in the given interval of time. Indeed, a breakdown lasted for approximately four (04) successive days.

The preventive inspections effectiveness is 0 . This low value could be justified by the fact that no preventive maintenance tasks was carried out on the pebble crushing area. Due to the long-lasting breakdown which occurred on the $03 / 09 / 2019$, no further preventive maintenance shutdown cannot be planned because of the need to make up the production to the expected goals.

The ratio of preventive to breakdown maintenance is 0.44 . The minimum recommended value is 16 . This extremely low value can be explained by the fact that no preventive maintenance work was performed on this equipment in the given interval of time. There were no preventive maintenance tasks on the pebble crusher because of the need to catch up with the production goals.

\subsection{The Single Stage Crushing Area Key Performance Indicators Results}

The maintenance effectiveness of the single crushing area is $99.54 \%$. The recommended minimum value is $95 \%$. This high value indicates that the corrective and preventive maintenance practices on the single crushing area were effective in the given interval of time. Beside the single crusher was removed from the circuit, which is only transporting the crushed ore to the ball mills through conveyor belt 6 (CVR 6).

The meantime between failure (MTBF) of the single crushing area could not be calculated because there was no failure during the given period of time. It is not possible to divide a number by 0 . Therefore, no solution was found.

The mean time to repair of the single crushing area could not be calculated because there was no failure during the given period of time. It is not possible to divide a number by 0 . Therefore, no solution was found.

The preventive inspection effectiveness of the single crushing area is 0.22 . This low value indicates that the preventive inspections frequency is too high since there has not been any single failure despite the absence of preventive maintenance tasks.

The ratio of preventive to breakdown maintenance of the single crushing area could not be calculated because there was no failure during the given period of time. It is not possible to divide a number by 0 . Therefore, no solution was found.

\subsection{The Primary and Secondary Ball Mill Key Performance Indicators Results}

The primary and secondary ball mills were installed in series and because of that both of the mills have the same working conditions, shut down hours, etc. Their maintenance effectiveness is $95.14 \%$. The recommended minimum value is $95 \%$. The actual value indicates that the corrective and preventive maintenance practices on the ball mills were effective in the given interval of time. The required maintenance effort decreased. The operating conditions improved as well.

Their meantime between failure (MTBF) is 190.5 hours. This relatively high value shows that the failure frequency decreased in the given period of time. The maintenance practices on the ball mills were effective.

The mean time to repair of the ball mills is 10.5 hours. This high value indicates that corrective maintenance practices were not effective in the given period of time.

The preventive inspection effectiveness of the ball mills is 2.27. This low value indicates that the preventive inspection frequency is a little bit high. The preventive inspection might have been ineffectively conducted.

The ratio of preventive to breakdown maintenance of the primary ball mill is 6.86 . This relatively low value indicates that the preventive inspections are ineffective or that some defects which could lead to serious breakdown and failures were not reported by the crew members to the maintenance planners and managers. The preventive maintenance might have been ineffectively conducted as well.

\subsection{The Plant's Overall Key Performance Indicators Results}

The maintenance effectiveness of the plant is $89.90 \%$. The recommended minimum value is $95 \%$. The actual measured value is slightly below the recommended value. It indicates that the required maintenance effort slightly increased in the given interval of time. The operating conditions also deteriorated.

The meantime between failures of the plant is 97.25 hours. This value is quite acceptable. The maintenance practices and mechanisms are effective. The failure frequency is quite stable.

The mean time to repair of the plant is 11 hours. This high value indicates that the repair tasks at the plant take too long. This could be explained by the fact that there is lack of utility equipment such as crane, truck cranes, forklift and loaders which are necessary for repair tasks. It is sometimes necessary to wait for three (03) hours before receiving the necessary and proper equipment for the repairs.

The preventive inspection effectiveness of the plant is 1.13. This low value indicates that the preventive inspection is high. This is not something bad at all for a plant of this age. The equipment needs to be inspected in order to early identify defects and fix them before they lead to catastrophic breakdowns or failures.

The ratio of preventive to breakdown maintenance of the plant is 11.66 . The recommended minimum value is 16 . The measured actual value is below the recommended value. This could be justified by the age of the plant. Indeed, this plant is one of the first ones in Burkina Faso and even in West Africa. Therefore, the equipment is more subject to defects, breakdowns and failures.

The backlog of the plant is 16 hours. This value is quite low and indicates that the coordination and synchronization between the maintenance crew and the planners is very god. Not many planned works remain undone for more than four 
days. During the given time, the only task which remained uncompleted is the elution heat exchanger plate washing. It corresponds to sixteen (16) man hours.

The percentage of scheduled man hours planned of the plant is $54.58 \%$. The minimum recommended value is $80 \%$. The actual measured value is below the recommended. It indicates that there are some work delays.

The percentage of scheduled compliance of the plant is $57.97 \%$. The recommended minimum value is $80 \%$. The measured value is below the recommended value. This means that the access to the equipment is slow. This situation slows down the preventive and corrective maintenance tasks.

The percentage of planning effectiveness of the plant is $18.43 \%$. The e recommended maximum value is $20 \%$. The measured actual value is below the recommended one and this is good. It means that the maintenance and production departments cooperation is effective. It also means that the planned requirements are well understood. The corrective and preventive maintenance practices are effective.

The percentage of rework of the plant is $9.24 \%$. The maximum recommended value is $20 \%$. The measured actual value is well below the recommended value. This means that there are effective work practices at the plant. The planning systems and mechanisms are well designed.

The percentage of failures investigated of the plant is $100 \%$. The recommended minimum value is $80 \%$. The actual measured value is above the recommended one. It means that the equipment reliability was stable and did not decrease. It also means that the plant managers and planners are continuously improving and optimizing their maintenance practices.

Table 1. Summary of the results.

\begin{tabular}{|c|c|c|c|c|c|c|c|}
\hline & $\begin{array}{l}\text { Old } 3 \\
\text { stages }\end{array}$ & $\begin{array}{l}\text { New } 3 \\
\text { stages }\end{array}$ & $\begin{array}{l}\text { Pebble } \\
\text { Crusher }\end{array}$ & $\begin{array}{l}\text { Single } \\
\text { stage }\end{array}$ & $\begin{array}{l}\text { Primary } \\
\text { ball mill }\end{array}$ & $\begin{array}{l}\text { Secondary } \\
\text { ball mill }\end{array}$ & General \\
\hline Total maintenance effectiveness: & $91.48 \%$ & $78.13 \%$ & $79.17 \%$ & $99.54 \%$ & $95.14 \%$ & $95.14 \%$ & $89.90 \%$ \\
\hline Mean time between failure (hours): & 43.28 & 42.19 & 342 & N/A & 190.5 & 190.5 & 97.25 \\
\hline Mean time to repair (hours): & 3.61 & 11.81 & 90 & N/A & 10.5 & 10.5 & 11 \\
\hline Preventive Inspection Effectiveness: & 3.83 & 15.9 & 0 & 0.22 & 2.27 & 2.27 & 1.13 \\
\hline Ratio of preventive to Breakdown Maintenance: & 19.55 & 2.13 & 0.44 & $\mathrm{~N} / \mathrm{A}$ & 6.86 & 6.86 & 11.66 \\
\hline Backlog (hours): & N/A & N/A & $\mathrm{N} / \mathrm{A}$ & N/A & N/A & N/A & 16 \\
\hline$\%$ Scheduled Compliance: & N/A & $\mathrm{N} / \mathrm{A}$ & $\mathrm{N} / \mathrm{A}$ & N/A & $\mathrm{N} / \mathrm{A}$ & N/A & $57.97 \%$ \\
\hline \% Planning Effectiveness: & N/A & N/A & N/A & N/A & N/A & N/A & $18.43 \%$ \\
\hline \% Rework: & N/A & N/A & N/A & N/A & N/A & N/A & $9.24 \%$ \\
\hline$\%$ Failures investigated: & $\mathrm{N} / \mathrm{A}$ & $\mathrm{N} / \mathrm{A}$ & $\mathrm{N} / \mathrm{A}$ & $\mathrm{N} / \mathrm{A}$ & $\mathrm{N} / \mathrm{A}$ & N/A & $100 \%$ \\
\hline
\end{tabular}

\section{Recommendations}

The TAPARKO mine plant is one of the first one in Burkina Faso and West Africa. Its maintenance crew consists of skillful and talented men. A key performance indicator (KPIs) analysis. This analysis could help the plant and maintenance managers to monitor the maintenance and maintenance planning performances. It could help keep the plants performances at the highest level and for the lowest cost.

A better cooperation of between the stationary equipment maintenance department and the mobile equipment maintenance departments could help considerably help reduce mean repair times. Indeed, one of the biggest issues that the plant's maintenance team has been facing is the lack of utility equipment such as truck cranes, cranes, forklifts, loaders and other equipment. This utility equipment is necessary for repair and during breakdowns, the maintenance crew has to contact and wait for the garage to send utility equipment. This waiting time can sometimes reach three (03) hours, delaying the repair tasks and critically reducing the production capacity at the same time. Another solution to this problem would be to provide the plant's maintenance team with its own utility equipment. The crew members would then be able to immediately intervene in case of failure or breakdown.

Feedbacks from the technicians would also help planners improve the maintenance schedule. Some feedback reports and work order sheets exist already at the plant's maintenance department. The problem is that these documents are returned late and unfilled most of the time complicating the task of data collection of the planners. Therefore, without feedbacks from the technicians, plant managers and planners cannot effectively adapt the planning to the realities of the field. A better cooperation between these stakeholders would help improve the maintenance performances of the TAPARKO mine's plant.

The reinforcement of the maintenance crew could also help boost the performances of the plant. The maintenance crew is sometimes overwhelmed by the great number of tasks that need to be done. This happens most of the time when several breakdown events occur at the same time and in different areas of the plant. In this kind of situations, crew members get exhausted quickly and become ineffective in the maintenance work. When they are tired, crew members also get more easily confused. Thus, the preventive and corrective maintenance would take much more time than the normal.

\section{Conclusion}

NORGOLD is one of the biggest and fastest growing worldwide companies in gold production. In less than one decade, NORDGOLD became one of the leaders of the mining sector. The company's assets span from Africa to the Eurasian countries. The company operates ten mines in four countries. One of them is the TAPARKO gold mine which was one of the first gold mines of Burkina Faso and of the region. 
One of the most strategic department of a mining site is the plant. The TAPARKO gold mine's plant consist of four main crushing area. There are two (02) "3 stages" crushing areas, one (01) single crushing area and one (01) pebble crushing area. The plant also consists of ball mills which grind crushed ore rocks, of tanks where the carbon-in-leach process is carried out. There is also a gold room where the gold recovery is performed through electrolysis.

The plant's maintenance department consists of a mechanical and an electrical crew. Each crew has got managers, superintendents, planners and supervisors. The maintenance crew mostly consist of very experienced and talented members. Except the managers and superintendents, most of the employees work on a 7/7 rotational basis. The daily workload is approximately twelve (12) hours.

The maintenance key performance indicators (KPIs) are very powerful tools that can help the plant managers monitor and track the maintenance performances against preestablished goals. These indicators should help increase the plant life and the labor productivity. They could also help reduce costly downtime, lower the total cost of time. Some particular key performance indicators (KPIs) such as the maintenance effectiveness, the mean time between failure and the mean time to repair were selected. The data was collected for thirty (30) days and these indicators were calculated. The results indicated that the maintenance at the TAPARKO mine plant is globally effective and that the managers, planners and crew members are very skillful and talented. Indeed, despite the age of the equipment, they do their best to keep it working in good operating conditions. However, the results could be improved by providing the plant's maintenance crew with its own utility equipment. Furthermore, a better collaboration between stakeholders would help reach better results. A reinforcement of the maintenance crew could also help current crew members who are sometimes overwhelmed by the large number of corrective and preventive maintenance tasks that need to be done.

\section{Acknowledgements}

I acknowledge Mr. Martial SORGHO, plant manager, Mr. Trevor BIWENGA, plant maintenance manager, Mr. Richard ILBOUDO, planner, Mr. Aliou OUEDRAOGO, planner, Ms. Leticia Madina OUATTARA, planner, Mr. Joel ILBOUDO, metallurgy engineer, Mr. Cyr YAMEOGO, mechanical maintenance supervisor, Mr. Serge BASSOLE, maintenance supervisor, Mr. Narcisse OUANGRAWA, technical drawer, the NORGOLD SOMITA company and all the maintenance crew and plant staff for the services rendered.

\section{References}

[1] Introduction to mining, page 1-24, www.cienciaviva.pt.upload.pdf, [Date of visit: 10/09/2019].
[2] Cross-Najafi, I. N. Gold Formation, Extraction, and Refining in the Sierra Nevada Mountain.

[3] Liliane, M. et al [2009] Empirical Analysis of Maintenance Performance Measurement in Belgian Industries, International Journal of production, pp: 1-12.

[4] Oliveira, M. et al [2016] Use of Maintenance Performance Indicators by Companies of the Industrial Hub of Manaus, Changeable, Agile, Reconfigurable \& Virtual Production Conference.

[5] Shrivastava, A. K., \&. Sharma, A. K. [2012] A Review Study of Jaw Crushers, IJMER, pp-885-888.

[6] Hulthen, E. [2010] Real-Time Optimization of Cone Crushers, Chalmers University of Technology, PhD thesis, 2010.

[7] JAGADEESH P. et al [2018] Fabrication of Low-Cost Ball Milling Machine, EPH International Journal of Science and Engineering, Vol 1 No 1.

[8] Balasubramanian, A. [2017] Size Reduction by Grinding Methods, University of Mysore.

[9] Gold extraction - Gold Mining - [2008] Washing, Amalgamation, Leaching, Smelting, www.geology.com, [Date of visit: 15/09/2019].

[10] Schubert, J. H. et al [1993] Performance evaluation of carbon in pulp plant, J. S. Afr. Inst. Min Metall., Vol. 93, no. 11/12, pp. 293-299.

[11] Kelly, A. Maintenance Strategy: Business Centered Maintenance. Oxford, Reed Educational and Professional Publishing.

[12] Dekker, R. [1996] Application of Maintenance Optimization Models: A Review and Analysis. Reliability Engineering \& System Safety, 51 (3): 229-240.

[13] Reason, J. T. and Hobbs, A. [2003] Managing Maintenance Error: A practical Guide, Ashgate Publishing.

[14] Campbell, J. D. Uptime: Strategies for excellence in Maintenance Management. Portland, OR, Productivity Press.

[15] Erkoyuncu, J. A. et al. Improving Efficiency of Industrial Maintenance with Context Aware Adaptive Authoring in Augmented Reality, CIRP Annals, V. 66, pp 465-468.

[16] FIIX, What Is Maintenance Backlog? www.fixsoftware.com/maintenance-backlog [Date of visit: 18/09/2019].

[17] SYMA Consulting, Sylvie, Rework vs Repair, www.symaconsulting.com/blog/rework-vs-repair/ [Date of visit: 18/09/2019].

[18] Torell, W. \&. Avelar, [2004] V. Mean Time Between Failure: Explanation and Standards, Schneider Electric.

[19] Serge et al, M. [2016] Motion Systems: An overview of Linear, Air Bearing and Piezo Stages, Adhesives Technology for Electronic Applications.

[20] Fortshoffer, M. S. [2017] Reliability Optimization, Fortshoffer's More Best Practices for Rotating Equipment. 